\title{
Appendix E: Cooperation in the Project Organization
}

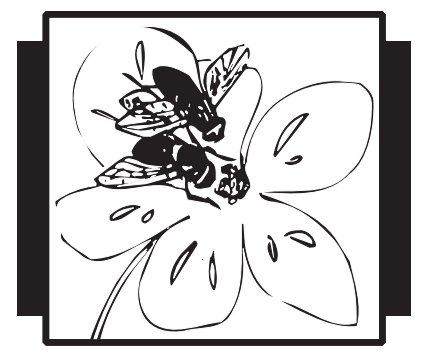

\section{E.1. Tool Sheet: Meetings}

What

Meetings are typical means of communication and joint problem solving and decision-making in projects. There are various types of meetings, each with their specific purpose, agenda, form, and relevant participants. We will describe work meetings (workshops) and steering/control meetings in this tool sheet.

Use - Where and When

Meetings are used in all phases of the project.

Method

Work Meetings

At work meetings, the participants do collaborative problem and task solving. It may include making a work description, 
brainstorming, coordinating solutions, and developing an agenda or a milestone plan. A work meeting is carried out when people can create a joint solution by contributing each with their knowledge, abilities, and strengths, when they can inspire each other, and when they are able to adapt their contributions. It is important to obtain synergy at a work meeting. The quality of the work is determined by the information that is present at the meeting. Qualified information is provided by people and the preparation process. Gillis from the Canadian Pacific Railways has developed a method of carrying out a work meeting, which is described in Figure E1.

The leader of the meeting is of great importance. The participants should experience the leader as being neutral to the subject of the meeting and to the participants (a moderator). He needs to be able to sense moods, to activate, to openly handle conflicts, to create a progression in the meeting, and to document the meeting in a well-structured manner. The leader of the meeting can be the project manager, but he might not be the right moderator. The project manager will (and has to) put his own mark on the project. At least, he needs to utilize his position as leader to make decisions on a number of matters.

Work meetings are held when needed. The subject can change, as can the participants.

\section{Launch Meetings}

A special version of the work meeting is the launch meeting, which is held at the beginning of the project and major phases of the project. The launch meeting serves the purpose of giving the project a flying start. In the big project group, the meeting should take the form of an information meeting with questions from the participants. The subjects of the meeting are the project's background and purpose, the organization of the project, the master plan, and procedures for project management. This needs to be followed up by launch meetings in the work groups, which will take the form of work meetings regarding the project planning and organization. In the smaller project group and in the bigger project's management group, the launch meeting can also turn into a planning workshop. 


\section{The workshop meeting}

- All participate on equal terms. Contributions are guided by participants' knowledge and skills.

- A moderator will guide the process and the participants' active cooperation. $\mathrm{He}$ is not engaged in the technical issues and results. He will not make technical decisions but will facilitate decision-making.

- Process methods are used for activating participants, for stimulating creativity, for conflict solving, for decision-making etc.

- Visualization tools are used to ensure shared perceptions.Talking to eyes and ears and hands.

- Group discussions are documented during the process - as a shared memory. Documentation is arranged so:

- that participants can follow the discussion process and revert to previous steps.

- that participants are focusing on the subject for discussion - but can see its relations to other subjects.

- that ideas/issues are recorded for later discussion.

- Documentation is either done by a referee, or everybody contributes.

- The meeting is in a room where walls are available for visualization and documentation. Brown paper, post-it, pictures, diagrams, video projector slides, video presentation etc. All important documentation is on the wall - visible to all participants. Removable furniture to be arranged in shifting lay-outs for new work patterns.

- Work pattern is varied in longer workshops. Short joint meetings for planning, structuring problems, brainstorming, evaluations, coordination/shared decisions. Break out into smaller groups for working on subjects and for documentation.

- After the workshop, the documentation is refined and arranged for use. Loose ends are listed for action. To-do list is distributed. The documentation on the wall is either transcribed or photographed for distribution.

\section{Preparation of the workshop}

- The moderator and the project manager and team leaders define purpose, issues, agenda, expected outcome and necessary preparation.

- Relevant participants are invited.

- Participants are informed about purpose, agenda, expected contribution preparation.

- Relevant materials are distributed before the meeting.

- Visual means are arranged.

- Meeting room is arranged.

- The moderator prepares a meeting strategy.

- Access to external communication is arranged.

Figure E1. The Workshop Meeting.

\section{Control Meetings}

Control meetings deal with the plan and its follow-up, as well as decision-making. Decisions are prepared at work meetings. Discussion of problems without preceding analysis should not take place at control meetings. Control meetings should be 
organized according to a fixed meeting schedule during the project work. Types of meetings are:

- Control meetings in the project core team. In smaller projects (less than seven to eight participants), all participants should participate. In bigger projects, the project manager, the group leader of each work group and participants controlling activities and economy should participate. The meetings are held regularly. The frequency is determined by the intensity of the project work.

- Meetings in the steering committee. The participants are members of the steering committee, the project manager, and the work group leaders. The meetings are held regularly - as a rule, after four to eight project core team meetings, and at phase shifts. Be aware to summon the steering committee when there is a need for special decisions or problem solving.

These regular meetings should be put into a schedule - a regular cycle. As the basic agenda typically is the same at the regular meetings, the participants should be the same to ensure continuity. Good communication is achieved when certain people participate in more types of meetings - so-called overlapping meeting structure. The meetings are carried out under relatively tight control cf. Figure E2. In addition to the regular control meetings, there will often be ad hoc meetings and follow-up meetings with suppliers, etc. They can be seen as a kind of control meeting.

\section{Meeting Minutes}

The meeting minutes are a documentation of the discussions and results of a meeting. They have multiple purposes:

- As a plan for further work and thereby a documentation of what needs to be done, by whom and when.

- As a (legal) agreement between parties. Either a documentation of the situation and stage, or a foundation for further work and obligations. 


\section{Project management meeting:}

- Agenda is listed and revised at the beginning.

- Present and missing participants are listed - for later recollection of who participated in decisions.

- Meeting proceeds according to agenda and schedule. Lengthy discussion of issues is avoided. They are postponed to separate workshops - with relevant participants.

- Chairman guides the discussion, recapitulates, formulates decisions, calls for position and decision.

- Minutes from the meeting are prepared - preferably only the decisions and actions, but background and arguments may be appropriate.

- The minutes are distributed immediately after the meeting. They are an agreement and they are information to non-participants.

- The minutes are formally accepted at next meeting and may be corrected.

The meeting is prepared:

- Chairman prepares the agenda - participants contribute.

- Agenda and materials are distributed in due time - e.g. on a meeting website.

- Each participant prepares for the meeting by reading the material or by discussing with other persons - to be competent at the meeting.

- Secretary arranges practical meeting facilities.

Figure E2. The Control Meeting.

- As a means of informing the people not participating in the meeting about agreements, plans, situation statements, ideas, etc.

- As a means of maintaining problems, ideas, and conditions that were brought up during the meeting and need to be addressed in the ongoing project work.

- As a way of documenting conditions and situations to be remembered later on in the project, when conditions might have changed.

The meeting minutes can have several forms:

- The decision minutes state the decisions and agreements that were made, subject by subject. It can briefly explain the conditions behind the decisions and agreements.

- The retelling minutes state the decisions and agreements that were made, and document the considerations and discussions, arguments, and circumstances. 
- The shorthand minutes give an exact report of what was said at the meeting - word by word, in a chronological order.

What form of meeting minutes to choose depends on the purpose and recipients. Work meetings are first and foremost reported by documentation of the professional results of the meeting - in an adapted form. A classic report from a work meeting describes the flow in the meeting, the decisions and important viewpoints, and conditions.

Control meetings requiring formality in appointments and negotiations need retelling meeting minutes. The participants need to approve the meeting minutes, if the meeting has been unusual, and if the meeting minutes will launch further actions with considerable consequences. The meeting minutes should be signed by the leader of the meeting as well as by the participants. Meeting minutes with legally binding agreements should be signed by every participant on every page. Absent participants are even able to sign and thereby accept the agreements. Another way of approving the meeting minutes is to put it on the agenda of the next meeting (and minutes).

There should be a standard for meeting minutes for each type of meeting - cf. Figure E3. It can be advantageous to use a standard form as well. The subjects of the project will be discussed at multiple meetings. It is important to note when subjects have been discussed. Therefore, it is important to refer to the subjects, in the same manner, every time. This can be achieved by a list of subjects corresponding to the structure of the project (work paths, milestones, main activities, phases). It should be possible to search and find all information regarding a subject across meetings - project work is always topic-oriented.

Meeting minutes serving as a basis for work and plans need to be distributed immediately after the meeting. Meeting minutes often explain work assignments to be done, who is doing them and when. Some participants do not remember this until looking over the meeting minutes. A good rule is that anyone who takes on responsibility immediately (at the meeting or reading the minutes) writes it in his calendar. Another advice is to write all 


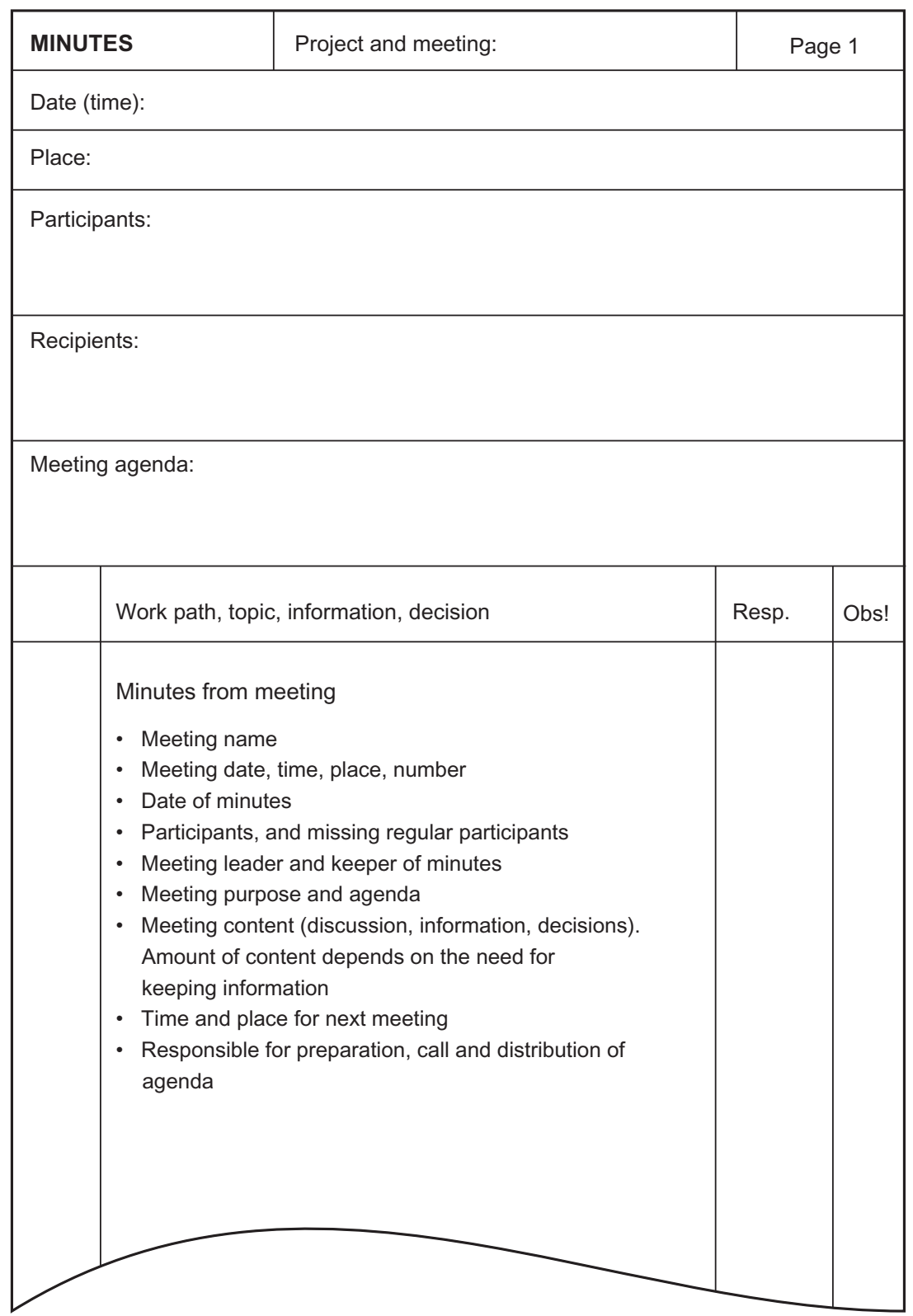

Figure E3. The Meeting Minutes. 
assigned tasks in a special appendix - a list of activities, which is updated at every meeting.

Meeting minutes are used as an official document and a common property of all participants. A participant in a meeting can also make his own notes and let it be part of the project documentation. These types of meeting minutes should structurally be separated from the official meeting minutes. They should, e.g., be entitled "personal meeting minutes" to avoid misunderstandings.

The above guidelines apply to projects where formality and a certain bureaucracy are necessary. In project groups, where practical needs overshadow formal needs, the meeting minutes can be simplified:

- The issue list is updated with a few notes about current issues.

- Decisions are maintained with a note - possibly with a note about prerequisites.

- Agreements about who is doing what and when are written on the activity list.

- A logbook with short notes about the course of the meeting is kept.

- If the project group has a workroom, the documentation can be posted on a board, using post-it notes and paper.

\section{E.2. Tool Sheet: The Good Teamwork}

\section{What}

To a large extent, project work functions as teamwork - in the project group and in the changing work groups. One of the challenges is to make the groups efficient as quickly as possible. Therefore, the project manager needs methods and tools for quickly developing teamwork in the groups.

This tool sheet focuses on the interaction in a group and thereby the loyalty of the participants to the group and the assignment at hand. Some of the participants also need to maintain a loyalty towards their organization, that being a user organization or a 
professional organization, with the responsibility of maintaining a qualified use of certain professional methods. This double-sided commitment needs to be taken into consideration when evaluating the behavior of the participants.

\section{Use - Where and When}

Developing collaboration in a group is especially important at the beginning of the project and in new phases of the project when the group structure changes. The collaboration should also be developed during the phases.

\section{Method}

Good teamwork is characterized by participants who feel committed to the task. Therefore, it is essential that every participant understand the task at hand. The participants need to know how to contribute to the solution, how to adapt their contributions to the other participants' contributions, and even help the others with their contributions. Figure E4 elaborates on this. Every perception,

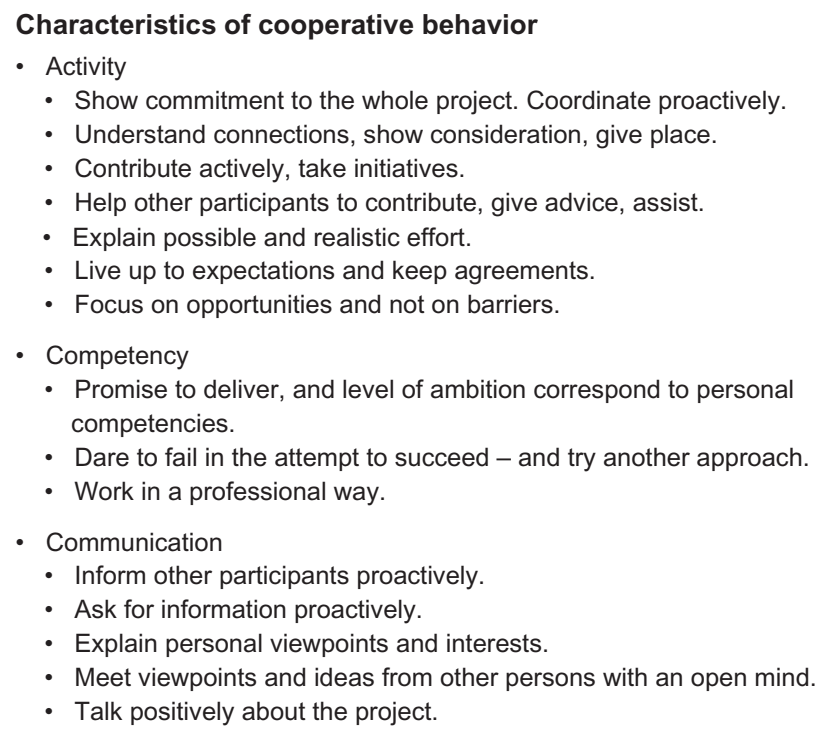

Figure E4. Examples of Collaborative Behavior. 
opinion and behavior affects the development in the group and determines norms for the group work. The form in Figure E8 can be used to determine the culture and collaboration in the group.

Teambuilding has three aspects:

- The mutual relations within the group.

- The participants' competencies and interests regarding the task and work. The professional role.

- The participants' competencies regarding the culture and interactions with other participants in the group. The so-called team role.

Developing relations can be seen as creating a social community. How far this should be taken depends on the need and interests of the participants. The desired culture can be described as a set of values for collaboration and behavior in the community and the image the group wants to portray to stakeholders.

Every participant has strong and weak sides and preferences, when it comes to behavior. It is important for the project manager and participants to be aware of this, in order to take advantage of the strong sides of the participants. There are methods to uncover strong and weak sides, e.g., Belbin's team roles as discussed in tool sheet D.2.

The good teamwork needs to be built from the beginning and maintained during the project. Figure E5 is a plan of how to do so.

\section{The Start}

Organizing the project and planning the work can partly be done at a planning workshop. This may be a good occasion to begin the teambuilding process, possibly in a special workshop. Figure E6 offers ideas for workshop subjects.

There are two team members, named "anybody" and "nobody". "Do not count on them to do work! 


\section{Initiatives for developing project team culture}

A. Basic activities at project start and maybe also later - to ensure conditions for the work:

- Sufficient project description.

- Competent project manager.

- Acceptance of the project from line managers. Agreement on priority and commitment.

- Define necessary competencies and allocate team members.

- Arrange physical facilities, project manual, web site etc. Make the project visible.

B. Activities at the beginning of the project:

- Employment dialogue between project manager and each participant.

- kick-off meeting.

- The group describes the project vision - visualized.

- Define shared values. Intended team image. intended work culture.

Defined individually by each participant and negotiated into a shared set.

- Identification of participants' style and preferred behavior.

Personal strong and weak sides. Personal points of attention.

C. Activities during the project:

- Evaluation dialogues between project manager and each team member about effort, contribution and motivation.

- Time-out evaluations. Resultats, process, cooperation, team culture.

- SWOT analysis (strengths, weaknesses, opportunities, threats).

- Introduction of new participants.

- Social gatherings. Celebrate successes, deliveries, and finalization.

- Visualize progress and results.

D. Activities at the end of phases and of project:

- Good bye and thank you to participants.

- Feed-back on performance.

Figure E5. A Model for Teambuilding.

\section{Issues in development of cooperation}

- Each participant's view on the project, commitment and expected personal benefit.

- Mutual expectations to work culture and collaboration in the project organization.

- Description of values and examples of good team culture.

- Intended reputation of the project and the project team.

- Possible barriers and obstacles for participant's effort. Loyalty problems and eventual conflicts related to the line organization. How to handle them?

- Each team member's strong and weak sides related to the project task. Opportunities for mutual support. Need for training.

Figure E6. Teamwork Issues. 


\section{During}

The term time-out is known from the sports world and can be transferred to the project group. From time to time - especially at milestones - the group can raise themselves above the daily work and discuss the efficiency of the work and the culture in the group. The subject is not the achieved results, but the process - roles and work division, the use of resources and time, teamwork, engagement, satisfaction, conflict management, decision process, etc. Very simplified, three questions should be asked:

- What are we doing well? How do we maintain that?

- What should be improved? How?

- Which conditions call for special attention?

\begin{tabular}{|c|c|c|c|}
\hline \multirow[b]{2}{*}{ Barriers to group effectiveness } & \multicolumn{3}{|c|}{ Is in my project? } \\
\hline & $\begin{array}{c}\text { Very } \\
\text { much }\end{array}$ & $\begin{array}{l}\text { To } \\
\text { some } \\
\text { extent }\end{array}$ & $\begin{array}{c}\text { Not at } \\
\text { all }\end{array}$ \\
\hline $\begin{array}{l}\text { - Unclear elements in project background, purpose, and scope. } \\
\text { - Participants have individual expectations, interests, needs, } \\
\text { viewpoints - different from other participants and deviating } \\
\text { from the official project goal. } \\
\text { - Insufficient organization and allocation of persons. } \\
\text { - Team members are allocated because they are avaliable } \\
\text { and not because they are the best. } \\
\text { - Team members are not committed - because of troublesome } \\
\text { work, no personal benefit, competition from other activities, } \\
\text { pressure from line organization colleagues or manager, } \\
\text { uncertainties etc. } \\
\text { - Lack of support and of prioritization from } \\
\text { top management. } \\
\text { - Unclear team member roles, overlapping tasks. } \\
\text { Insufficient communication. } \\
\text { Mistrust of project manager's competency and authority. } \\
\text { Blinkers. specialist thinking, egoism. } \\
\text { - Barriers to change. } \\
\text { Personal antipathy, differences in behavior. }\end{array}$ & & & \\
\hline
\end{tabular}

Figure E7. Obstacles in the Group. 
To support these group evaluations, it is a good idea to use evaluation forms with a number of questions. Figure E7 shows a relatively simple scheme, which may help the evaluation and discussion. It only focuses on obstacles. Figure E8 shows a more

\begin{tabular}{|c|c|c|}
\hline Conflict cluture & & Collaboration culture \\
\hline $\begin{array}{l}\text { Shared goal but unclear and not fully } \\
\text { accepted. Pursue individual goals. } \\
\text { Hidden agenda. }\end{array}$ & $\begin{array}{l}\text { Understanding of goal } \\
\qquad \begin{array}{llll}12 & 245\end{array}\end{array}$ & $\begin{array}{l}\text { Task and goal are understood and accepted - after a } \\
\text { debate. Individual interests are considered. }\end{array}$ \\
\hline $\begin{array}{l}\text { Ignorance of each other's knowledge and } \\
\text { technical competence. Little mutual } \\
\text { understanding. Antipathy, prejudice. }\end{array}$ & $\begin{array}{l}\text { Mutual knowledge } \\
\qquad \begin{array}{lllll}1 & 2 & 3 & 4 & 5\end{array}\end{array}$ & $\begin{array}{l}\text { Know each others knowledge and technical competence. } \\
\text { Attitudes, behavior, and feelings are considered. }\end{array}$ \\
\hline Ideas are killed. Defense mechanisms used & Openness & Receptiveness toward ideas, proposals, and new ways. \\
\hline Hidden actions for initiative. Mistrust. & 12345 & Willing to give. Trust. \\
\hline $\begin{array}{l}\text { Criticism is embarrassing and creates } \\
\text { tensions. Is avoided. }\end{array}$ & $\begin{array}{l}\text { Criticism } \\
123455\end{array}$ & Presented in a constructive way and discussed. \\
\hline $\begin{array}{l}\text { Marked by indifference and formalities. } \\
\text { Being on guard. }\end{array}$ & $\begin{array}{l}\text { Atmosphere } \\
12345\end{array}$ & Hard-working, committed, kind, informal. \\
\hline People working separately. & $\begin{array}{l}\text { Mutual support } \\
\begin{array}{llllll}1 & 2 & 3 & 4 & 5\end{array}\end{array}$ & Real care for each other. \\
\hline $\begin{array}{l}\text { Some persons dominate. Sidetracking. } \\
\text { Talk past each other. Do not listen. }\end{array}$ & $\begin{array}{l}\text { Communication } \\
12345\end{array}$ & $\begin{array}{l}\text { All participating. All contributing to keeping track of the } \\
\text { goal. Active listening and direct feedback. }\end{array}$ \\
\hline $\begin{array}{l}\text { Does not ask for contribution and advice. } \\
\text { Does not stick to the point. Contributions } \\
\text { are kept back. }\end{array}$ & $\begin{array}{l}\text { Resource utilization } \\
\begin{array}{lllll}1 & 2 & 3 & 4 & 5\end{array}\end{array}$ & $\begin{array}{l}\text { Call for ideas and contribution. Listening. All suggestions } \\
\text { are discussed. Mutual support in work situations. }\end{array}$ \\
\hline $\begin{array}{l}\text { Conflicts are avoided or brought to } \\
\text { win-loose decisions. }\end{array}$ & $\begin{array}{l}\text { Conflict handling } \\
\qquad \begin{array}{lllll}1 & 2 & 3 & 4 & 5\end{array}\end{array}$ & $\begin{array}{l}\text { Call for different viewpoints and discussion. Nobody } \\
\text { dominates or side-tracks. Work for shared solutions. If not - } \\
\text { possible decisions are made in a democratic way. }\end{array}$ \\
\hline $\begin{array}{l}\text { Little clarification before decisions. Fast } \\
\text { dominance decisions. }\end{array}$ & $\begin{array}{l}\text { Decisions } \\
12345\end{array}$ & Participants discuss pro et contra. Agreement of solutions. \\
\hline $\begin{array}{l}\text { Initiatives and action without coordination } \\
\text { - to satisfy own interests. } \\
\text { Passive - "not my table". }\end{array}$ & $\begin{array}{l}\text { Action } \\
12345\end{array}$ & $\begin{array}{l}\text { Initiatives and actions are coordinated with other } \\
\text { participants. Initiatives for solving problems or mitigating } \\
\text { risks - e. g. by signaling the responsible person. }\end{array}$ \\
\hline $\begin{array}{l}\text { Unclear who should do what. } \\
\text { Agreements are broken. }\end{array}$ & $\begin{array}{l}\text { Agreements } \\
12345\end{array}$ & $\begin{array}{l}\text { Clear roles and activity allocation. Agreements are } \\
\text { documented and kept or replaced by new agreement. }\end{array}$ \\
\hline $\begin{array}{l}\text { Fight about leader roles. Disagreement } \\
\text { about policies. Win-loose situations. }\end{array}$ & $\begin{array}{l}\text { Leadership } \\
12345\end{array}$ & $\begin{array}{l}\text { Acceptance of agreed leader roles and policies. Leadership } \\
\text { may change depending on phase and activity. No fights - } \\
\text { the results are important. }\end{array}$ \\
\hline $\begin{array}{l}\text { Analysis is not done in the team - but } \\
\text { outside. }\end{array}$ & $\begin{array}{l}\text { Process analysis } \\
\begin{array}{lllll}1 & 2 & 3 & 4 & 5\end{array}\end{array}$ & $\begin{array}{l}\text { Plans, methods, collaboration, work culture are evaluated } \\
\text { and discussed. }\end{array}$ \\
\hline
\end{tabular}

Figure E8. Evaluating the Culture in the Project Group. 
elaborated model that can be used to describe the culture of the project group. Each participant fills in the scheme by marking 1-5 on the scale at each question. The evaluations are compared and the participants explain their answers. Conflicting evaluations will start a debate that can help to solve problems.

Figure E9 shows an analysis form that zooms in on the behavior of each participant during the teamwork. This method requires an observer who can take down what happens during the group work. This should include explanations of what is happening in the group. Finally, the observer gives the participants feedback on the teamwork.

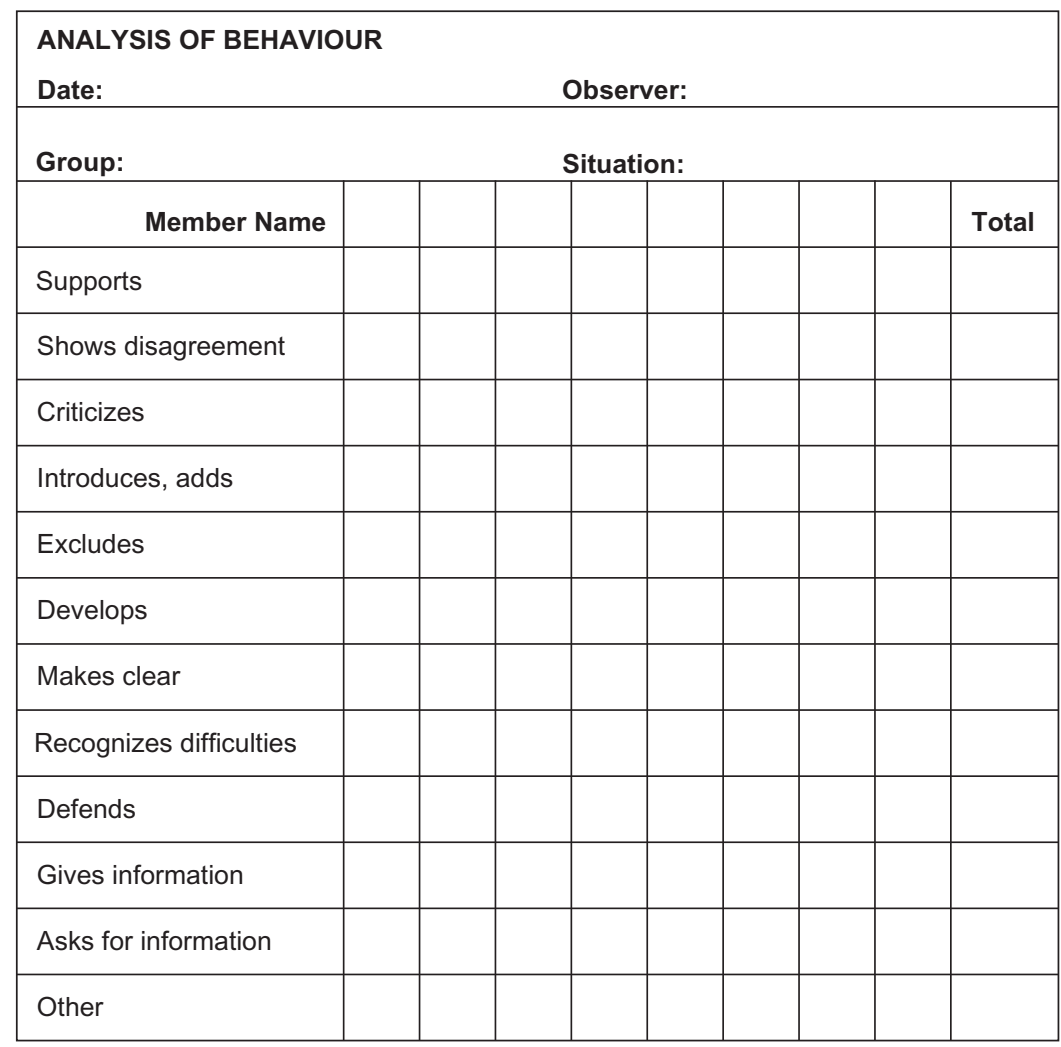

Figure E9. Analyzing the Behavior of the Participants During a Meeting. 


\section{Ending}

At the end of the project and during the final social gathering, it is possible to do a final evaluation of the teamwork, which the participants can learn from. This is also an opportunity to deepen relationships as a means for each participant of creating a broader personal network.

\section{References}

Belbin, R. M. (1981). Management Teams - Why they succeed or fail. Butterworth - Heineman

Wilemon, D. L. \& Tamhain, H. J. (1979). Team Building in Project Management. Proceedings, PMI Symposium, Atlanta.

\section{E.3. Tool Sheet: Dealing with Conflicts}

\section{What}

Conflicts during the project can be professional conflicts between participants - such as disagreements about the existence, name, and importance of a problem, disagreements about goals to achieve or prioritize, or about the consequence and value of alternative options affecting the solution. Another type of conflict is formal conflicts dealing with behavioral norms and different perceptions of rules, roles, and responsibility (territories) in the project work. There are also language conflicts - misunderstandings, professional views and expressions (language). Finally, there are personal conflicts - as results of antipathy and distrust. Disagreements often arise because of uncertain and vague conditions for project work, which can create anxieties within the group.

Conflicts are often perceived as being nonproductive and disruptive, but many of them can actually be turned into constructive challenges and mutual sparring. A conflict or tension often leads back to the tone and attitude in the dialog between the participants. 


\section{Use - Where and When}

Dealing with conflicts or tensions is necessary in all phases.

\section{Method}

\section{Disagreements}

Disagreements deal with concrete cases and take place between people, groups or organizational units. In theory, disagreements are simple. The disagreement has a subject and involved parties. In practice, it is more complex and less clear - see Figure E10.

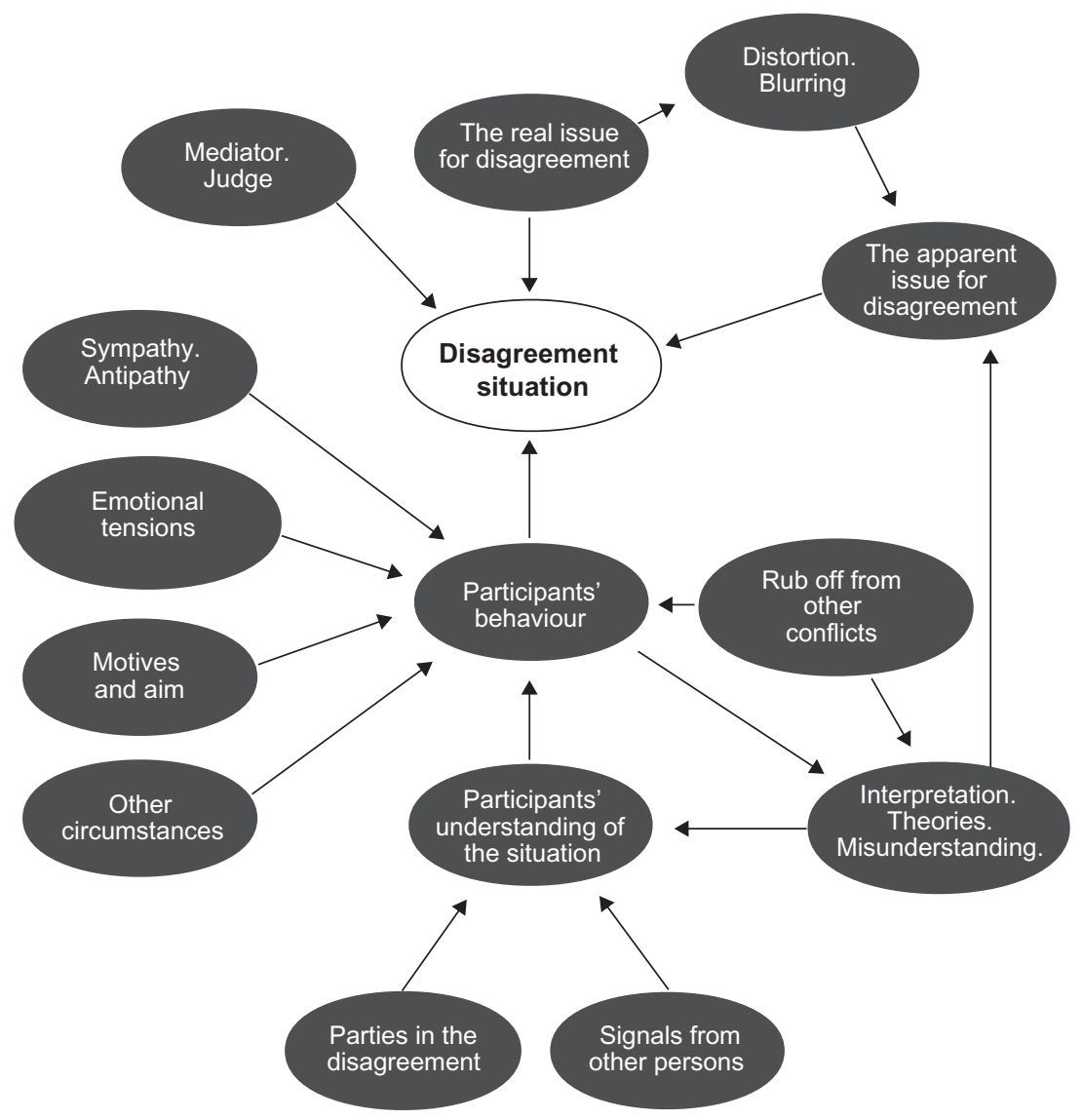

Figure E10. Characterizing the Disagreement. 


\section{Reasons for emotional tensions}

- Competition, jealousy, need for power and influence

- Importance of personal status and prestige (and "keeping face")

- Need to assert oneself and to win just now, e.g. to maintain success or as revenge for earlier defeat

- Personal stress level - general and actual, influenced also by other problems in work situation and home situation

- Acceptance of different goals and interests in the project organization - and of the need for collaboration

- Acceptance of holistic view

- Understanding of the importance of the problem

Figure E11. Reasons for Emotional Tension.

A disagreement can be twisted and blurred, and it can arise from another disagreement. One disagreement can create assumptions, antipathies, and wishes for revenge, which can fuel a second disagreement.

Disagreements can be based on misunderstandings, incorrect interpretations of behavior, and assumptions about the others party's intentions and motives. The collaboration might end up having participants who see each other as enemies.

A participant's engagement in conflict handling is often determined by emotional tensions. The tension is created for numerous reasons, cf. Figure E11, which depend on the participant's perception of the situation. Therefore, it can be difficult to predict a participant's reaction to tensions and disagreements.

\section{Dealing with Disagreements}

How a participant handles a disagreement can be described by four elements:

- Degree of frustration, when the disagreement is recognized

- Understanding of the real subject and reason for the disagreement

- Behavior and action to handle the disagreement

- Understanding of the desired, possible, and obtained outcome from the situation 


\begin{tabular}{|l|c|c|c|}
\hline \multirow{4}{*}{ Active effort } & $\begin{array}{c}\text { Force. } \\
\text { Win/lose situation }\end{array}$ & $\begin{array}{c}\text { Negotiation. } \\
\text { Good compromise }\end{array}$ & Shared solution \\
\cline { 2 - 4 } & Forced compromise & $\begin{array}{c}\text { Mutual adaptation. } \\
\text { Bad compromise }\end{array}$ & $\begin{array}{c}\text { Mediation. } \\
\text { Good compromise }\end{array}$ \\
\cline { 2 - 4 } Passive effort & Drawing lots & Forced adaptation & Voluntary adaptation \\
\hline & \multicolumn{2}{|c|}{$\begin{array}{c}\text { Destructive } \\
\text { attitude }\end{array}$} \\
\hline
\end{tabular}

Figure E12. Types of Behavior in a Conflict Situation.

The behavior often changes during a disagreement. A participant may change his way of reacting to an opponent's behavior or handle the disagreement differently than before, cf. Figures E12 and E13. The duration and course of the disagreement are highly affected by the participants' need to mark their positions. Conflicts may open up when a participant publishes his opinion, attitude or decision in a disagreement or takes action. The participant might publish his opinion to start a discussion and show his willingness to receive new information and arguments that might change his mind. However, a decision or an action may in some situations imply that the person has passed the point of no return. A retreat means losing face. In such situations, it might help to open up by adding new aspects, new considerations and information.

The participants' actions generally serve as means to reach a (reasonable) solution, but sometimes the participants have other motives behind their actions. A participant who actively wants to start resolving the disagreement can profit from analyzing the disagreement, cf. Figure E10. Also, the participant can build a platform for his/her own action. It may consist of four parts:

- The position of strength: This is based on the participants' level of power, cf. Figure E14. As seen in the figure, there are other forms of power than the formal authority gained from position. It is possible to change own and other participants' level of power by unfolding different kinds of activity, cf. Figure E15. It is important to note that advocates of 


\section{Conflicts are influenced by how the involved persons:}

- experience the need for shared decision.

- Understanding of own and other people's competency related to the subject

- Understanding of consequences for and relations to other people's work

- Confidence in own decisions.

- see differences in understanding of project goals and consequences of solutions (solution quality).

- Understanding of and attitude to differences of opinion (information sources, technical terminology)

- Understanding for other people's situation and interests

- Level of consideration.

- are able to act.

- Drive (too fast, too slow)

- Information before action.

Little information and one-sided information about an issue make it easy to decide for some people. There are apparently no complications. Conflicts are recognized after published decision and action - regrettably. Earlier recognition of potential conflicting interests require communication with stakeholders and ability to understand their world.

\section{Participants' constructive behavior in conflict situations}

- Do not argue blindly, listen to the other part.

- Avoid competition and win-lose situations. Viable results count.

- Do not change your mind just to avoid a conflict.

- Avoid conflict suppressing methods.

- Avoid to 'buy' participants with deviating opinions.

- Be critical toward acceptance reached too fast and without arguments.

- See differences of opinion and ideas as stepping stone to better decisions.

- Believe that you can make this team more efficient.

Figure E13. Reactions to a Conflict Situation.

rational project management consider some of the methods in this figure unethical. The methods have been included for the sake of completeness.

- The formulation and motivation behind the initiative to resolve the disagreement. It is important to emphasize the necessity and importance of the initiative, to indicate an acceptance of possibly selfish motives, to find a level of sufficiency and sincerity, and to clarify discomforts and drawbacks.

- The timing. The timing can be inconvenient because of other urgent matters. There is also the option of trying to gain time in order to strengthen own level of power. 


\section{Participants' personal power rest on different bases}

- Knowledge about users' world

- Knowledge about technology, engineering/design, and solutions

- Knowledge about company strategy and policies

- Broad experience

- Formal authority

- Control of rewards and sanctions

- Personal relations

- Educational status

- Personal power of penetration

- Communication capability

- Time, energy

- Information control (meetings, agendas, minutes, reports)

- Group solidarity.

Figure E14. Levels of Power in a Collaboration.

- Strategy. A strategy is important in order to find the right way and to solve the disagreement.

Possible strategies in a conflict:

- Mutual problem solving (consensus): The participants try to find a joint solution through the exchange of viewpoints and arguments - possibly by finding alternatives and adapting to one another. This strategy is the most ideal, but it can be very time-consuming, which is why other strategies might be used instead.

- Dominance: The majority settles the disagreement (possibly by voting), or the participant (possibly the project manager) who has the highest level of authority makes the final decision. It can also be settled through persuasion, where one participant tries to convince another with (good) arguments.

- Negotiation and compromise: The solution is reached through negotiation and compromise, which can turn into a trade and power struggle. "I'll agree to this, if you agree to that." Personal interests and selfish goals will most likely overshadow the trade. 


\section{Political activities for gaining infulence}

- Use authority, sanctions, and rewards. Force and order.

- Obtain support from a man of power.

- Establish sponsor role (project owner). Use lobbyism.

- Establish alliances with colleagues.

Create shared benefits. Make a deal about benefits (horse trading)

Create joint situation. Agree on support.

- Take control of a critical resource.

Control allocation of money and resources. Have special competences at disposal.

Control reporting. Control incoming information ('guard').

- Control the decision process.

Choose decision criteria and limits. Select the alternatives for final decision. Control information about the alternatives.

- Control the meetings.

Arrange agenda, topics and their sequence. Choose participants. Choose meeting time and place. Chair the meeting or appoint the chairman. Write the call for meeting and control distribution of information before the meeting. Arrange contacts and influence on participants beforehand. Write the minutes.

- Use bureaucracy and control.

Do or control the planning. Establish procedures.

- Control information.

Control the distribution of information. Censor or withhold information.

Distort information.

- Delude.

Conceal goals, plans, and motives. Show two faces, surprise.

- Play games.

Split and control. Derail things. Divert attention. False alarm.

Figure E15. Political Activities to Gain Influence.

- Avoidance: One tries to talk around and twist the problem or delay decisions. The motive can be to hope that others will resolve the conflict instead, or to overshadow the conflict with a new problem.

- Smoothing out: One focuses only on the elements where everyone agrees. Positive elements are the only focal area and problems are avoided. Here, the motive can also be the hope that others will resolve the problem.

- Closing: The conflict is closed, e.g., by separating the disagreeing participants. The conflict still exists, but it gets diffused. 
- Removing: The conflict is removed, e.g., by changing goals, solutions, and evaluation criteria.

Conflicts can be treated by using an outside person, a mediator. This requires an agreement about the procedure for handling the conflict. The mediator can be a judge who has the power to make a concrete decision or to create procedures and rules that will regulate the conflict. It can also be a mediator or consultant, who conveys communication and seeks out alternative solutions. The mediator makes admissions seem easier and creates a situation where no participant loses face.

Many conflicts arise between two or more participants. The project manager and team often do not have a direct part in the conflict, even though they might believe so. This is important because the project manager's role in the conflict should be to create a dialog and start a process for solving the problem. The project manager should often not act as a judge or have any direct part in the conflict. If this happens, the problem should be escalated to a higher management level.

It is necessary for participants of a project group as well as the project manager to be aware of disagreements and try to counteract unfortunate circumstances. This is done through effective communication, seeking to mediate in difficult situations and through analyzing the collaboration. It is especially important to be aware of methods of dealing with conflicts that may ruin the quality and reputation of the project or stall the momentum of the project. It can be methods where decisions are postponed - often because somebody demands a new analysis (or discover "new" ideas or new considerations) or questions decisions already made.

\section{E.4. Tool Sheet: Decision Process}

\section{What}

Decisions are the result of a process, which ends in a manifested decision or an action. Influence on the decisions is obtained by affecting the process, its participants, and its information. 


\section{Use - Where and When}

Dealing with decision processes is relevant in all phases of the project.

\section{Method}

\section{A Decision Model}

A basic model of a decision model shown in Figure E16. Project management is seen as a house with two floors. Selection of opportunities, decisions and actions are made on the first floor. On the ground floor, the foundation for decisions is built - analysis, information gathering, idea creation and testing ideas. On the ground floor, guests can be invited to add inspiration, knowledge, quality, and ideas to the project - the outside world is used for knowledge and inspiration. This requires no bindings, because consensus is not the goal on this floor. The first floor, on the other hand, is where consensus is achieved through discussion of advantages and disadvantages. The idea behind this model is to make the participants aware of where they are in the decision process.

\section{Four Basic Ideas}

There are four basic ideas (models) of how solutions are chosen and decided on in a project. They express different approaches to and views on decision processes:

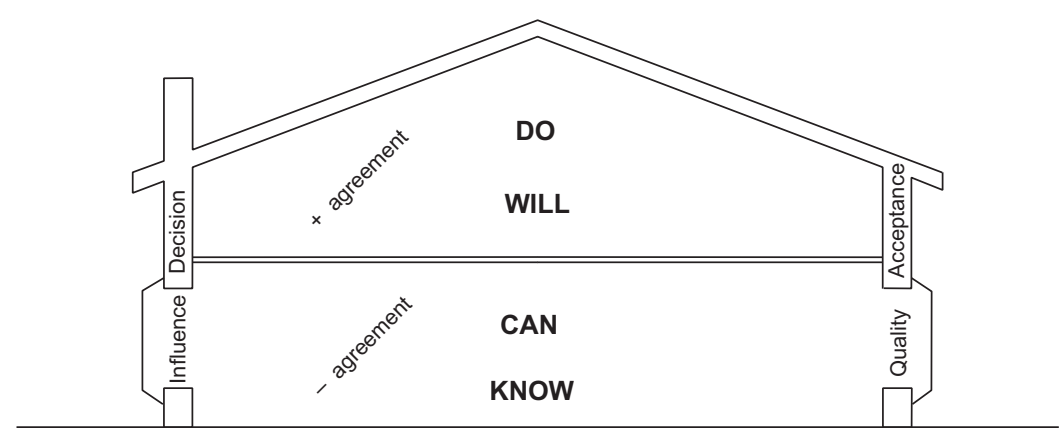

Figure E16. A Decision Model (Source: Bech, 1990). 
- The power idea: I/We know what is needed, how the solution should look and how it should be implemented - "my way!"

- The rational idea: There must be a right solution to this. An objective analysis of the need and systematic search or design should be able to find it - and then it is carried out.

- The political idea: The solution should be found through power struggles around the project. We listen to and follow those with power and influence - and we find a compromise that they will accept.

- The searching/learning idea: The solution needs to be found through trial and error. Ideas and ambitions have a say, but a realizable and useful solution should be found through experiments and temporary solutions that will be improved along the way.

\section{The Garbage-Can Model}

The idea of methodical project planning and well-considered project management also entails the idea that decisions are made when the necessary foundation has been created and when appropriate occasions have been arranged, such as a meeting with the project manager or the steering committee. The so-called garbagecan model (March \& Olsen, 1986) looks at the decision process in a slightly different way:

- The decision makers face many problems during the project, requiring a certain amount of energy when they appear.

- The decision makers meet solutions that are looking for problems to solve. This may help certain decision makers to manifest themselves, or solutions just happen to be visible at the point of decision.

- The decision makers' energy and time for solving problems change over time. Each individual has different perceptions of the problems that arise, and has changing needs of manifestation. 
- The decision makers make decisions alone or together at arranged or random occasions.

According to the garbage-can model, many decisions are made at presumably random occasions. The explanation is that a decision can be made by one or more persons, when the following conditions are met at the same time: The person has acknowledged the problem and its magnitude, has identified a feasible solution, has an occasion to decide, and has the energy (will, interest, time) to solve the problem. Sometimes, people try to arrange a decision meeting in order to solve a certain problem, but the energy is just not there. The four elements can occur at random occasions - at the lunch table, on a trip or at a random meeting. Figure E17 gives some advice on influencing a garbage-can situation. Christensen and Kreiner (1991) have a similar advice for projects in loosely coupled organizations.

\section{Decision Process}

Deliberately hidden decisions are the hardest ones to deal with. They occur when one or more participants identify a problem, examine it and make a decision, without anyone else knowing. After having made their decision, they summon everyone for a meeting to discuss the problem. They will be open to suggestions on how to solve the problem, but they have already made up their

\footnotetext{
Some advice about decision processes

- Think the garbage-can model.

- Let others get the honor - as long as

- Make problems visible and urgent.

- Make solutions visible and attractive.

- Arrange occasions for decision.

- Spend time and be present, exploit the energy, when it is available.

- Influence influence, influence. you get the best solution.

- Investigate and understand other persons' motives.

- Develop your power base (expert, trustworthy).

- Find experienced advisors.

- Continue - there is a new day tomorrow.

- Create alliances.

- Discuss several alternatives.

- Do not go for consensus.

- Show the main thread.
}

Figure E17. Advice on Decision Processes. 
mind. They might already have taken actions that will ensure their solution as the right one. Indications of such an occurrence are often that the participants talk more about solutions than the about actual problem. They have made up their mind and want to convince instead of listening. It is a waste of time to argue against them. It would be more fruitful to concentrate on participants who are willing to listen and analyze. One should be attentive throughout the decision process and be active from the beginning. The most influential person is not the one who attends the formal decision meetings, but the one who knows where the decision is made.

This brings us to the decision process. Figure E18 shows activities of a decision process, where the project group prepares for a decision with the project owner, project manager, and steering committee. The preparation activities may lead to selection of an informal decision that in fact turns out to be the final decision, implying that the subsequent decision meeting only is a formality. Figure E19 shows a model for recommendation of decision and documentation of the decision.

In the various project groups, many decisions will be made by individuals who follow their own ideas. When decisions are made, a number of requirements and considerations should be fulfilled, such as professional insight, the decision's impact on other parts of the project, the economic scope of the decision and its influence on the work plan. The quality of a decision depends on how the individual participant perceives the quality of the assumptions underlying the decision, estimates his own knowledge and experience, understands the project goal, and perceives the decision's impact on other parts of the project. It also depends on the participant's acceptance of the goal and consideration of the interests of others.

Joint decision-making is characterized by the participants' recognition of the need for a joint decision - contrary to making a decision alone. It is also characterized by the differences in opinions regarding the problem, goal, and consequences. The need for joint decision-making is powered by a work plan that creates an overview of the project and binds the participants together 


\section{Activities in the decision process}

- Quality assures the proposal. Review and hearing of key-persons and decision makers.

- Ride hobbyhorse and leave fingerprints. Dialogue with key persons who have special requirements and are particularly critical.

- Influence opinion formers. Those who answer for the technical solution and those who answer for the political aspects.

- Arrange the process with the formal decision makers to ensure that they keep in step.

- Information in advance to stakeholders. Avoid surprises and being overwhelmed. Inform about aim and solutions.

- Prepare hearing. Distribute information or arrange information meeting. Arrange with speakers at the meeting.

- Hearing meeting - for information, explanation, and reaction. Present and describe in understandable terminology. Avoid overselling - describe the consequences and the benefits. Explain the alternatives and the arguments. Give the participants time for consideration and discussion. Arrange feedback and comments, so that people are heard.

- Give place for influence.

Leave choice between alternatives to the stakeholders - but ensure that the alternatives are suitable. The hearing meeting may be arranged as a workshop.

- Decision meeting.

Distribute information and recommendation. Possibly, information meeting or dialogue with each participant beforehand - to ensure understanding. Give room for influence. Arrange meeting process with the chairman. Prepare minutes of the meeting - the decision and the conditions, the main arguments, uncertainties, and assumptions. Arrange announcement and implementation.

- Announce the decision.

After agreement with decision makers. Maybe they should announce the decision.

Figure E18. Activities in a Decision Process.

through a joint utilization of resources (time and money, among other things). Communication and a positive attitude are conditions for a good, joint result. The procedure needs to be discussed beforehand, when difficult decisions have to be made. The decision process will proceed much easier, if the evaluation criteria and procedure are agreed on. Figure E20 lists the individual participant's possibilities of influencing decision-making.

A classic approach is to evaluate several solutions and several criteria (goal, wishes). Every criterion is weighed and valuated on a scale with points. Does this method lead to objective decisions? 


\section{Recommendation and decision basis}

- Project manager's recommendation

Precise and clear. Explain possible alternatives and preferences.

- Arguments for the recommendation Including the main thread - connection to earlier and coming decisions.

Refer to detailed documents.

- Points of attention

Critical success factors. Uncertainties related to conditions, interested parties and consequences.

Project manager's (proposed) actions. Potential consequences of no decision now.

- Action plan for implementation of the decision.

One page. Detailed information may be attached

Figure E19. Preparing for a Decision.

Influence on results is achieved by:

- taking initiatives.

- formulating problems and actions.

- producing solutions (ideas).

- working for acceptance through arguments and communication.

- defining evaluation criteria.

- participating in evaluation and decision.

Figure E20. Participants' Possibilities of Gaining Influence.

Probably not every time - but the method can make the decision process more transparent for the participants involved. Everyone is forced to structure their thoughts and arguments, and the method can stimulate a debate about conflicts regarding subjective choices and the value of criteria and solutions. No matter what, there may be participants who act on selfishness.

A decision is followed by action. The responsibility for implementing the decision should, therefore, be placed. However, this is not always the case. Sometimes decisions substitute actions. Participants deliberately do not define who should carry out the decision and when. In other cases, an unnecessary replacement action is decided on, e.g., to propose further analysis or to await a 
report. Participants create an action that does not generate any momentum or useful result.

Another matter is the durability of decisions. Political processes and considerations dominate in some decision processes. This means that yes/no decisions are not completely clear. Participants are there just to legitimize the decision process, but they are not committed decision makers. The effects can be re-prioritization as a result of a shift in politics, and because those in power make decisions single-handedly without regarding others.

A third matter is how the participants are motivated to make decisions, to maintain them and create momentum - instead of just throwing ideas and problems around, or only attending to own interests or postponing decisions. A method is to create a sense of urgency, unity, winning mentality and understanding of the project as a whole. It is also important to reward the participants for joint collaboration and not just individual achievements. Below is a list of advice for project managers:

- Maintain contact with persons with power and influence try to sense the atmosphere.

- As the project manager you should position yourself - either as the real leader of the project or as an instrument for those in power.

- Work for informal acceptance before formal decisions are made.

- Clarify and settle possible disagreements and acceptance from those in power, before a decision meeting.

- Be humble - respect others' capabilities and authorities.

March (1994) discusses many of the behavioral aspects of decision-making processes dealt with above. D'Herbemont and César (1998) discuss projects with political tensions and have several models and directions on how to analyze and work on the attitudes and behavior of stakeholders. 


\section{References}

Bech, N. (1990) Competency borders in the project - Peace or quarrels? (in Danish). Symposiet Projektledelse 90.

Christensen, S. \& Kreiner K. (1991). Project management in loosely couple systems (in Danish). Jurist-og Økonomforbundets Forlag.

D’Herbemont, O. \& César B. (1998). Managing Sensitive Projects. Macmillan Business, UK.

March, J. G. (1994). A Primer on Decision Making, How Decisions Happen. The Free Press.

March, J. G. \& Olsen, J. P. (1986). Garbage can models of decision making in organizations. In J. G. March \& R. Weissinger-Baylon (Eds.). Ambiguity and command, pp. 11-36. Cambridge, Ma. Ballinger.

\section{E.5. Tool Sheet: Communication Plan}

\section{What}

The communication plan is used to clarify the interested parties' need for information about the project, and also for planning the involvement of interested parties via information, hearings, dialog, and involvement in decisions. The plan will secure involvement of interested parties during the project and appropriate control of information around the project.

The communication plan aims to create understanding and acceptance among important interested parties. In this way, changes throughout the project will happen with consideration for and support from interested parties. This plan concerns all external information. The plan is not just the project management's dialog with interested parties. Dialog between interested parties who have conflicting interests can be crucial in order to handle conflicts and power relations, and is therefore just as important. 


\section{Use - Where and When}

The first plan should be prepared already at the first project planning, and the plan is to be dynamic throughout the project. The opinion of interested parties change, the project develops, and new realizations arise throughout the process. The communication plan should, therefore, be updated throughout the project.

\section{Method}

The starting point is the analysis of interested parties, which gives an idea of who the parties are, how the project and its results will affect them, what attitude they have (and will have) towards the project, and what kind of influence they will have on the project regarding acceptance and understanding of the project and its solutions.

The communication plan can be prepared considering several aspects:

- The project approach is prepared considering anchoring, understanding, and acceptance. The communication activities serve as a basis for working on the solution, and the process features communication milestones.

- The project approach is prepared on the basis of technocratic considerations. Milestones in the development and implementation process are seen as good occasions for dissemination of information and for dialog.

The plan itself can be visualized in several ways:

- Arranged for each interested party with the above-mentioned needs; communication themes in each phase; the chosen forms of communication.

- Arranged for each phase. Communication activities are included in a milestone-and-activity plan for each phase. 
A framework for the communication plan can look like this:

What needs to be said:

To/with whom (interested parties):

By whom:

\section{How:}

When:

With what effect:
Key messages and themes of the dialog.

The recipients or their representatives, and/or persons who influence the interested parties.

Spokesmen and persons with influence.

Use of different, well-chosen communication methods.

Well-chosen time, with suitable frequency.

Measurable results:

Did the messages reach the receivers (number of participants or readers, etc.)?

To what degree did the receivers notice, remember and understand the messages?

Did the communication have any effect on changing of attitudes?

The plan includes the choice of suitable information and dialog methods and channels. From one-way communication channels like a website, newspaper, newsletter, posters, models, CDs, and videos to methods, such as focus groups, hearings, and reviews. A comprehensive plan can be quite extensive, and we recommend that project management seek professional assistance when preparing the communication plan.

\section{E.6. Tool Sheet: Learning}

What

Learning during a project happens both individually and collectively (in formal and informal groups) and leads to a mixture of 
silent and explicit knowledge. Complicated teamwork during a project can be especially hard to deal with; but it is nonetheless also what creates a good learning process - both consciously and unconsciously. Learning as a process ultimately leads to competencies.

The aim of this tool sheet is to strengthen the learning process during a project by (1) uncovering where and how actually learning happens, and evaluating necessary learning competencies and by (2) pointing out methods that may strengthen the learning process - both individually and collectively.

\section{Use - Where and When}

There is a difference between learning from a single project and learning from multiple projects. In the first case, gathered experience is typically made at the end of the project, but it is a good idea to have reflection meetings during the project - regarding the project as a whole and as special subjects. Learning as a whole is especially important when it comes to preparing the organization for future project demands.

\section{Method}

In the following, a method of acquiring an overview of an organization's project competencies is given, followed by a method for uncovering how learning actually happens. In the subsequent two sections, a number of methods for learning during and across projects will be presented.

\section{How Are the Organization's Project Competencies?}

Learning happens within many fields and not just within the management of time and economy or the development of the project group. Learning from working with interested parties is vital, as are elements that enhance motivation and energy during a project. We suggest using the elements of the five-by-five model to discuss where there is a need for a strengthened learning effort.

The form below, with an example, can inspire to work with existing competencies. 


\begin{tabular}{lcl}
\hline The project elements & $\begin{array}{c}\text { Scale } \\
1-5 \\
(1=\text { poor })\end{array}$ & \multicolumn{1}{c}{ Elaboration } \\
\hline Overall evaluation. & $3-4$ & $\begin{array}{l}\text { Many participants have } \\
\text { broad competencies, but } \\
\text { some shortages when it } \\
\text { comes to new types of work. }\end{array}$
\end{tabular}

The competency to define a project task.

The competency to handle outside matters.

The competency to work with interested parties.

The competency to handle resources.

The competency to create systematic procedures (approach, organization, and control).
3 Fine, when a project is well defined from the outside or from above, but they are not good at looking behind the defined task.

4 Good networks and abilities to have a finger on the pulse.

3 Good abilities to create backing and support from the start, but not that good at keeping in contact with interested parties and giving them updates.

4 Creates great engagement in project groups.

4 Established corporate routines exist with respect to approach, organization, and control, but there is a need to be able to adapt to the needs of individual projects.

When it comes to individual competencies, a list of the relevant strengths and weaknesses within different areas can be made. At first, a quite simple description should be made in order to start formulating which competencies are needed. Later on, a step-bystep evaluation of competencies can be used, such as suggested by 
Dreyfus and Dreyfus (1986): novice, advanced beginner, competent doer, clever doer, and expert.

As to the collective competencies, it is often not noted when a project group has dealt with a difficult situation by collaborating internally and externally. A way of covering these competencies is to describe a number of examples of difficult situations that a project group has dealt with. The appreciative inquiry method highlights these positive stories (Hornstrup \& Loehr-Petersen, 2007).

It would be natural - as a part of the evaluation - to compare existing competencies with competencies that are expected to be needed in future projects.

\section{How Does Learning Happen Today?}

The form below, with an example, may inspire the project group to uncover how learning takes place.

\section{Individual learning}

There is the career process, where an employee starts out with a few project management tasks and gradually meets more challenges a sort of apprenticeship without a systematic reflection or training process.

A project model with phases, organization and management routines will work as a basis for novices in project management. It is used without engagement and does not work as a dynamic learning tool.

Good informal exchange of experiences among project participants and project managers.

\section{Collective learning}

A collective evaluation at the end of the project is made - but without greater engagement or effect.

A coherent analysis and evaluation of the project process or comparison of projects are rarely made. 
The learning models mentioned in Section 5.7 can help asking relevant questions; for instance, one can examine how reflection happens, both individually and collectively. Kolb's model (1984) can be used to examine how a proactive, systematic experiment in learning new things is carried out. Nonaka and Takeuchi (1995) describe different ways of collective learning based on a combination of silent (tacit) and explicit knowledge, and how this can help uncovering how learning happens now and how it can be improved.

\section{Learning During the Project}

This section contains a number of learning methods for the project manager and team during the project.

\section{Individual Learning and Developing Competencies}

The technological development requires all participants to have professional knowledge and understanding. It is also important for all participants to understand how the company creates value, and to be able to act in agreement with that towards customers and affiliates. This is related to the fact that companies today have a close cooperation with their customers.

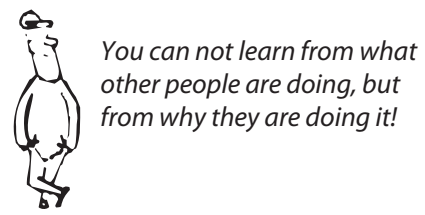

In reference to Dreyfus and Dreyfus' model, it is suitable to carry out training courses for novices, and a mixture of formal teaching and practice for advanced beginners and competent practitioners. Advanced practitioners and experts need stimulation through individual reflection and collective exchange of experiences.

The choice of methods also depends on the subject. For instance, learning about planning and controlling time and costs will include some sort of quantitative analysis, whereas learning about the reaction of interested parties is based on personal experiences.

\section{Teacher, Coach, and Mentor}

It is a good idea for a project manager to find a coach or sparring partner. It can be a consultant, a boss or another project manager. 
Conversations with a coach can deal with feedback on behavior and handling of situations, and discussions about coming management situations. The coach should not simply say "this is what I would do" or "this is what you should do". The coach should guide the project manager to reflect by asking questions that would shed light on the actual problem, and on possible solutions/approaches and their consequences. Learning requires patience.

Not everyone is a good coach. It takes time and willpower to be available and to take initiative, even when the project manager does not. It requires insight and understanding. Sympathy and confidence are important. The coach should be able to discuss situations when someone loses face as well as unpleasant situations in general. It is a good idea to receive formal coach training.

The role as a teacher is slightly different. The teacher is the most knowledgeable. From a teacher, the project manager can receive experience and good advice. For example, the project manager can work as an assistant to a more experienced project manager, who takes on the role as a teacher. The project manager can also be assigned a teacher during a project. This demands a flair for teaching. Excellent project managers are not necessarily good teachers.

A mentor is a person who is good at talking about future plans, ambitions, and personal development - based on a picture of strong and weak traits. The mentor has life and professional experience.

\section{Tandem}

Sparring with another project manager, supplemented with workshops across projects, is also a method. In this way, project managers can do self-analysis and present problem situations to each other. Problem interview or appreciative inquiry can be used as methods to analyze situations, and to teach the participants how to analyze difficult and challenging situations themselves. An analysis of symptom and cause is used to identify the roots of a 
problem and to see the road to a successful result. Be aware that the problem interview may be a psychological challenge for the person being interviewed. It is difficult to present embarrassing situations.

\section{Problem Interview}

At the problem interview, the person sits down with a listening group, and the process is as follows:

1. The person explains his interpretation of the problem and its circumstances - guided by an interviewer.

2. Then, the person turns his back to the listening group and listens. The group discusses what they have heard. They can ponder over possible causes and hypotheses, but they cannot propose possible solutions. The person may not comment.

3. The next step is for the person to think about what the listening group has said - in order to reach a changed or confirmed perception of the situation, and especially to reach an identification of the causes of the problem. The person can discuss the causes with the listening group and pose elaborating questions.

4. Afterwards, the person can tell what he will do to solve the problem or to avoid the problem next time. The listening group is allowed to give advice.

\section{Appreciative Inquiry}

The basic idea is that learning works the best when using the person's strong traits and initiatives. Possibilities are in focus, not limitations. The process is as follows:

1. Describe what works well in the project.

2. Describe a desired future - where everything runs smoothly.

3. Select the most important areas of improvement and choose solutions.

4. Implement the solutions.

Source: Hornstrup \& Loehr-Petersen, 2007 


\section{Time-out Evaluation}

Every project participant learns from the project work, but the learning can be strengthened by reflection and staging a collective reflection process. We call it time-out - just as a handball team would stop the game to discuss it. When learning happens during the project, it can be used directly throughout the rest of the process. When reflection happens as an evaluation at the end of the project, the learning can be used in following projects.

A model for time-out learning is shown in Figure E21. Notice that the questions avoid criticizing people and focus on the case. When improvements are needed, it is necessary to find the causes of flaws and mistakes, in order to improve for the next time. Figure E22 shows an example of a visual illustration of a causeeffect chain. This way of searching for causes might point to some people, but it is important to direct the discussion and talk towards ideas for constructive actions and tools instead. Figure E23 shows what to remember in evaluations during the project.

\section{The Learning Diary}

In a learning diary, the problems and learning situations of the week are written together with the lessons learned. It is a good

\begin{tabular}{l|l|l}
\hline \multicolumn{2}{|l|}{ Model for time-out reflection } & $\begin{array}{l}\text { How can we keep that } \\
\text { and repeat it? }\end{array}$ \\
\hline $\begin{array}{l}\text { Wood (success)? } \\
\text { ghat was really } \\
\text { better? }\end{array}$ & Why? & $\begin{array}{l}\text { How to do next } \\
\text { time? }\end{array}$ \\
\hline
\end{tabular}

- Describe successful results and activities - and where they were in the process.

- Describe deviations from agreements, goals, quality, plan,budget - and when they were identified.

- Describe immediate causes. Ask WHY?

- Find causes to the causes. Ask WHY? - until you find the root causes.

- Were there signals on the way? Which - and how should we have reacted?

- Find solutions to the root causes. Ask HOW?

Draw cause-and-effect diagrams

Figure E21. A Model for Time-out Reflections. 
Cause-effect diagram (example: new IT system)

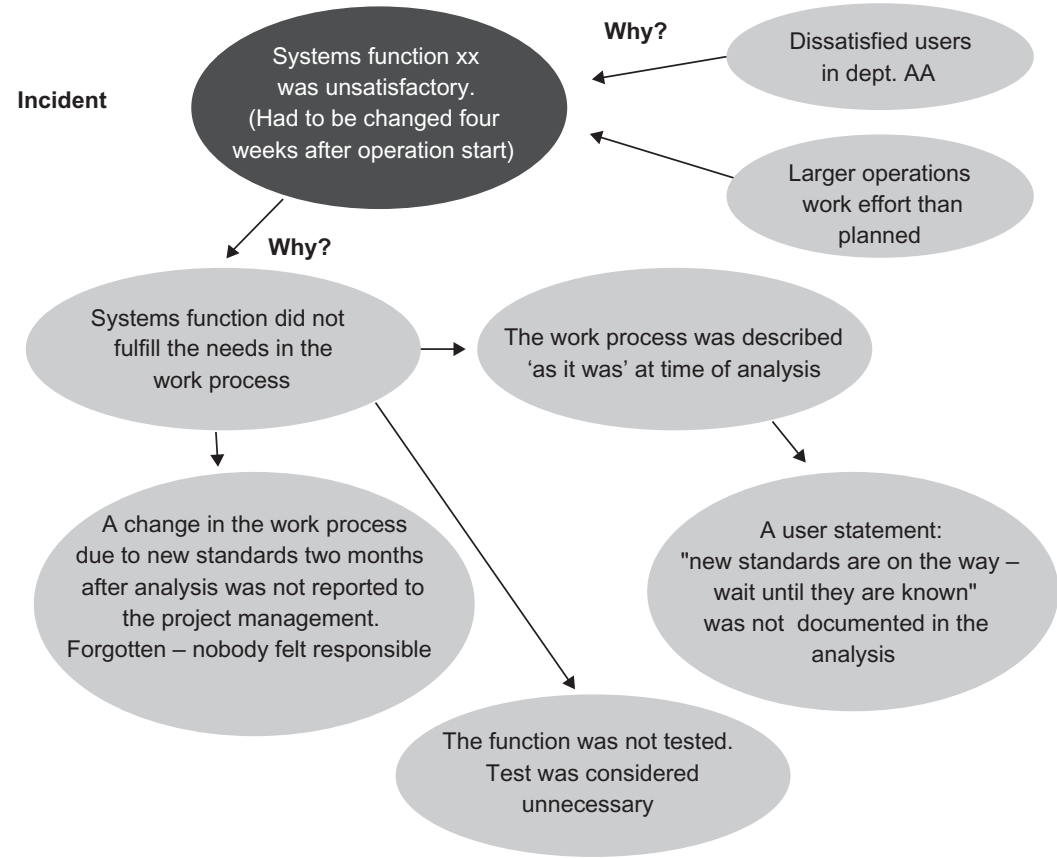

Which of these causes are root causes? How to do next time?

Figure E22. An Example of a Cause-effect Analysis.

way of measuring performances, results, and progress - and it can be used at personal development conversations. It encourages taking moments for reflection.

\section{The Project Manager Should Learn to Learn}

Learning on the job requires persistency and proficiency of the project manager. A starting point can be to describe the project's special needs for management effort and form. This will sharpen the project manager's arrangement of sparring with others and use of a coach.

Learning on the job is "on demand," i.e., when the problem is present. But this should be supplemented with a learning rhythm. It can be regular meetings with a coach or in a learning group. It can be the learning diary, where the project manager notes the learning situations and theorems of the week. 


\section{Evaluation during the project:}

- Project status

What is done and finished?

- Project relevance and goal Interested parties' attitudes?

Changes in project basis and conditions?

Is the project still relevant?

Should scope and goal be changed?

Points of attention in the environment?

Need for anchoring and commitment?

- Work quality

Is the product quality satisfactory - will the product fulfill the goal?

Will the success criteria be fulfilled?

Will the stakeholders be satisfied?

Points of attention?

Need for quality assurance?

- Adherence to plan and budget

Observance of time schedule?

Observance of project budget?

- Control and efficiency

Methods, systematic and reasonable approaches?

Speed?

Work effort and contributions from participants?

Qualifications in the project organization?

Roles, coordination and management, communication, collaboration culture?

Commitment and quality consciousness?

Communication with stakeholders?

Understanding and acceptance?

Project visibility?

Figure E23. Cues for Evaluation During the Project.

One should learn to learn! Most of us can easily enumerate our own experiences - what we have worked on and know. But have we learned more personal theorems to be remembered next time? This demands reflection on own experiences - cf. Figure E24.

The project manager of a new extensive control and information system (controlling a transportation company's logistics) was chosen from the systems development department in the company. She had a background in the user world, but for a very short period, so her knowledge of that world was limited. She had managed smaller system development 


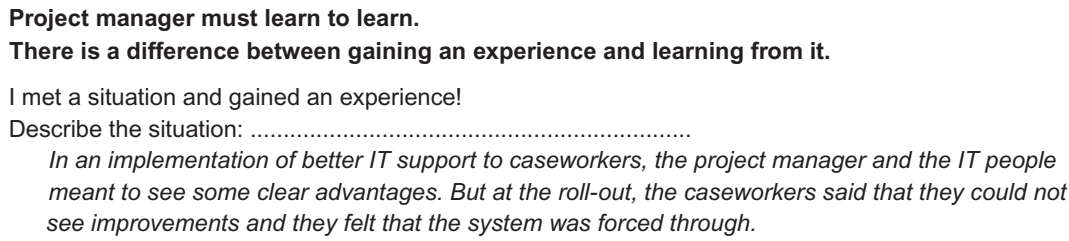

Describe the challenge:

Which considerations concerning method, approach, and action did I have? I saw the acceptance of the requirement specification from the steering committee and the competent IT developers as sufficient for good result.

What did I (actions)?

What was the result?

What is my experience?

This project is not just IT, but the organization and business process development as well. Middle managers and primary users were informed along the way, but not asked for test and acceptance. Their criticisms were first articulated at the implementation.

--- and what is the learning?

From the beginning, I should have arranged active support from management and have arranged user involvement for test and feedback.

Figure E24. A Method for Reflecting on Management Situations.

projects and had shown leadership qualities. But the management and she thought that there was a need for support in the project management job - to be given by a project management consultant. An important element was to guide the management of the preliminary planning and concept workshops with a large number of participants. It was important for her to state herself as the leader and become visible. A couple of subsequent support tasks were to help her 'elevate herself' into becoming an overall project manager for a number of other project managers who had their own subprojects. It was hard for her not to manage the subprojects herself. Another task was to guide her to spend most of her time doing extrovert management, in order to secure the whole implementation process. As a part of this, it was important for her to gain knowledge about the user environment, in order to lead a trustworthy dialogue.

\section{Learning Across Projects}

In this section, we will describe thoughts and methods about learning between project managers preparing for future projects. It deals with conveying experiences and learning from finished 
projects as well as providing outside knowledge and developing project methods. It is not enough for each manager or participant to gain knowledge and competencies through their work. A company's competitive edge may often be found in the employees' ability to work together on solving complicated and dynamic tasks in a holistic way. The company contains both silent and collective knowledge, which can be hard to describe and can only be developed through joint reflection and experimentation.

\section{The Learning Environment}

In addition to methods, the organizational environment also influences the actual learning. A hierarchical organizational structure furthers the learning in every department, and makes it more difficult to learn across the organization, even though there are many daily opportunities to do so. Measurement systems for performance, including the selection of reward systems, are examples of formal systems that affect the individual and the group. But also informal work forms and organizational culture influence the attitude towards learning.

\section{Knowledge Sharing Must Be Arranged}

Knowledge sharing does not happen on its own - it should be arranged. It requires creating a work culture where an appropriate amount of knowledge sharing is a natural step in solving tasks. Procedures and systems should provide an environment for the knowledge sharing to take place. But directives and commands will not stimulate knowledge sharing. Many examples from practice show that knowledge sharing is fragile. Misinterpreting information from a colleague in another department can lead to product development going in a wrong direction, or to the delivery of a client order not corresponding to the client's wishes. Examples from a study of companies from different industries show that there are methods to improve knowledge sharing including IT systems as vehicles for explicit sharing of experiences and joint reflection (Riis, 2004). 


\section{Learning Groups}

Project managers can form groups with other project managers or a network with people who want to take part in mutual development. A network can be both internal and external. In a learning group, project managers can present problem situations as well as successful situations to each other. They can analyze the causes and make theorems. The group can also invite teachers, bosses, and project managers from other companies for lectures and dialog.

Such "exchange of experience groups" relies on participants who are prepared to both give and receive. If the group is driven by a few enthusiasts who are the only ones keeping the group going, it will only last until the enthusiasts quit. If participants time after time do not show up because of other pressing tasks, the group will die fast. On the other hand, it is good to break up when the yield is low.

\section{Project Days}

Another method is to arrange internal project days - seminars where the project culture, effectiveness and productivity in projects are discussed among bosses and project managers, and where good project examples and perhaps also failures are reviewed.

\section{Development Conversations}

The development conversation between the project manager and his personal manager is an important tool to develop project managers. It is important to be aware of the basis for how the staff manager evaluates the project manager. The staff manager's sense of how the project manager is doing might be limited because the project manager works for and with other managers and clients. Therefore, the staff manager should collect information about the project manager's performances and use it correctly.

\section{Database with an Overview of Project People's Competencies}

Many companies have worked on identifying the company's competencies and have started out by mapping the employees' 
individual competencies. This may lead to a knowledge account. The employee becomes aware of his competencies, which are evaluated as part of the annual development conversation. The competencies of all employees in the company are visible. This can encourage employees to draw on others' knowledge and experience, but the database is most often not sufficient. Personal networking is also important.

\section{Knowledge Database}

The companies' project manuals and toolboxes for the project managers are a part of the methods that may help collect experiences. Methods can be described and exemplified from projects. Storytelling about projects and occurrences during projects can be read. But experience shows that project managers benefit more from talking with experienced people and using them as guides.

\section{A Joint Perception Is Useful As a Frame of Reference} for Knowledge Sharing

It is not enough for each person to interpret knowledge and experiences in their own way. There needs to be a joint perception of the context that the exchanged knowledge is a part of. It is not solely to have a clear image of the company's goals; there also needs to be a joint acknowledgment of how the internal collaboration works and of future challenges, which is emphasized by Senge (1990).

A study of business processes in Danish companies (Morsing \& Nickelsen, 1999) showed that some processes went wrong. A further analysis revealed that some people were not aware of what went on in other departments. If there had been a joint perception of the departments' mutual collaboration in the process, the unfortunate developments could have been avoided. Knowledge sharing is not just a question of passing on knowledge from one person to another; it is also about creating a joint perception of processes and their prerequisites.

There are more methods for development of a joint perception in a group of people from different parts of a company. The group 
can draw pictures of the process (process diagrams) and explain and discuss the processes. People can describe their department's desired situation and discuss what this means for the other departments.

Problem matrices can illustrate how problems can spread to other departments. Company simulation games offer participants an opportunity of experiencing a complicated interaction with more senses than just watching a PowerPoint presentation. It is especially effective when the situation being treated resembles the participants' daily tasks. Simulation games can be used to create a joint recognition of the situation at hand and to try out and discuss new solutions. In this way, a joint understanding of advantages and limitations to a new work form or system will appear, cf. Riis, Smeds and Landegehm (2000).

A joint image does not necessarily mean that all participants agree. On the contrary, the joint image can contain an acceptance of different opinions. Besides giving insight into existing work forms and mutual collaboration, the joint frame can also be used to create a joint perception of future challenges, and to develop ideas of where the company can and should move.

A project management system on the intranet supports joint planning. At a smaller order-producing company, a planner has used an IT system to manage customer orders. By putting the system on the intranet, where everyone has access to information, many more were actively involved in planning the customer orders. In this way, the system served as a focal point for joint planning of customer orders.

\section{A Company Competency in Joint Reflection}

Because joint competencies are mostly based on silent knowledge of informal interactions across the company, it is important to work on creating a larger, joint awareness of the competencies in the company. It can be expressed by two central elements in Kolb's learning circle - i.e., the ability to reflect and to experiment.

In many companies, there is only a vague perception of how informal interactions across departments really work. Achieving a 
joint recognition of this will create greater awareness of the nature of the interactions and the core competencies brought into play. A sports team uses video recordings of themselves and others to strengthen joint learning. Such awareness can be compared to theoretical work forms - as a basis for developing competencies in a new direction.

\section{References}

Dreyfus H. L. \& Dreyfus, S. E (1986). Mind over machine, The Power of Human Intuition and Expertise in the Era of the Computer. Free Press, New York.

Hornstrup, C. \& Loehr-Petersen, J. (2007). Appreciative Inquiry A constructive method for positive changes (in Danish). DJØF Forlag.

Kolb, D. A. (1984). Experiential Learning, Experience as the Source of Learning and Development. Prentice-Hall, Inc. USA.

Morsing, M. \& Nickelsen, N. C. (1999). Migration of knowledge (in Danish). CO-industri \& Dansk Industri.

Nonaka, I. \& H. Takeuchi (1995). The Knowledge Creating Company - How Japanese Companies create the Dynamics of Innovation. Oxford University Press, New York.

Riis, J. O., Smeds, R. \& Van Landeghem, R. (Eds.) (2000). Games in Operations Management. Kluwer Academic Publishers.

Riis, J. O. (2004). Key competencies and conditions for learning in the knowledge society's companies (in Danish), Danmarks Erhvervsråd.

Senge, P. (1990) The Fifth Discipline - The art and practice of the learning organization. Century Business, UK. 